\title{
Ms-Evolution in Cu-Zn-Al SMA. Predictable Temperature and Time Actions on Parent Phase
}

\author{
A. Isalgue and V. Torra
}

CIRG-DFA-ETSECCPB-UPC, Campus Nord B-4, 08034 Barcelona, Spain

\begin{abstract}
Recently an increased interest has been noticed for order effects in Cu-based SMA. For instance, on the transformation temperature $\mathrm{Ms}$ values and its evolution after heat treatments and quench type effects. Usually, the experimental Ms values after quench fluctuate around $\pm 2 \mathrm{~K}$. The interest for continuous actuators needs a more reduced and, in any case, predictable fluctuation domain. In this work, by using high resolution in temperature, time and resistance measurements on a $\mathrm{Cu}-\mathrm{Zn}-\mathrm{Al}$ alloy $(1.48 \mathrm{e} / \mathrm{a})$, the results establish a distribution of the evolution in two main actions: a relatively short time and a long time tail effects. Two temperature dependent time constants have been determined from the experiments, with different activation energies $(13630 \mathrm{~K}$ and $10330 \mathrm{~K})$. The two actions might be associated to different ordering processes. Furthermore, the experimental results allow to describe a representative model that can be used to predict the Ms evolution with temperature and time. The differences between simulated and experimental results for the $\mathrm{Ms}$ is about $\pm 0.15 \mathrm{~K}$ for temperature-time evolutions near room temperature.
\end{abstract}

\section{INTRODUCTION}

Smart materials carry out simultaneous functions as sensors and actuators. One of them, the memory alloys, are distinguished by a martensitic transformation between metastable phases [1-2]. The high temperature crystallographic form (or austenite) is coherent with a large number of variants in the low temperature structure (or martensite). This allows various macroscopic shapes in the low temperature phase to coexist with only one high temperature shape (Shape Memory Effect).

The applicability of the shape memory material for on-off actions needs only a poor reliability. However, in a continuous and smooth control, a small hysteresis and the rigorous stability of the transformation temperatures is needed: a time guarantee is required for constructed devices. For a given alloy, the transformation temperature depends on thermal treatments or, in equivalent form, on the microstructure and on the degree of atomic order in the material (see, for instance [2-5] and related references).

Recently, an increasing interest in the degree of atomic order and its evolution with time in memory alloys has been detected [6-10]. A careful analysis (accuracy $\pm 1 \mathrm{~K}$ ) of the evolution of the transformation temperature needed to establish the limits of guarantee of the Thermomark can be found in [11]. The analysis of the experimental results indicates that the transformation temperatures fluctuate "pseudo-randomly" in long term observations within relatively reduced margins $\left(\delta M_{S} \approx \pm 2 K\right)$. In general, the changes in $M_{S}$ have been associated to many causes: atomic order ( $\mathrm{B} 2$ and $\mathrm{L} 2_{1}$ in $\mathrm{Cu}-\mathrm{Zn}-\mathrm{Al}$ alloys), domains of order, elastic dipoles, dislocations (creation, movement and evolution), ...

In this work, by carrying out continuous observations of the electrical resistance in austenite phase and using a rigorous control and programmation of the temperature, it has been possible to quantify the behaviour of the material near room temperature. The analysis of the experimental results allows phenomenological rules which regulate the behaviour of the material as function of time and room temperature. The results establish that the "uncontrolled" fluctuations on the transformation temperature can be strongly reduced $\left(\delta \mathrm{M}_{\mathrm{S}} \approx \pm 0.15 \mathrm{~K}\right)$.

\section{EXPERIMENTAL}

A computer controlled electrical resistance measurement system which allows a maximal resolution and reproducibility of around $0.05 \%$ in resistance (stress free sample) has been used. We have used a four-wire technique with inversions of the current to avoid the effect of parasitic thermal emf. The averaging of 256 double readings has been done with the actual sample resistance (about $2.2 \mathrm{~m} \Omega$ ) and the low current used 
$(0.2 \mathrm{~A})$, to achieve the resolution and reproducibility stated. Using the maximum resolution does not allow for the detection of evolutive phenomena taking place in less than $600 \mathrm{~s}$.

The temperature has been controlled with a resolution and reproducibility of $\pm 0.005 \mathrm{~K}$, between 263 and $373 \mathrm{~K}$, by means of computer controlled Peltier elements, as described in [12]. Continuous observations have been carried out during more than 3 years with the temperature controlled. Starting from several temperatures $T$ in a steady state, cooling to martensite state $(263 \mathrm{~K}$ ) and subsequent heating produces a complete cycle of the transformation-retransformation and the $\mathrm{M}_{\mathrm{S}}$ value (resolution near $0.05 \mathrm{~K}$ ) can be determined from the experimental cycle $R=R(T)$.

The sample used (single crystal of $\mathrm{Cu}-\mathrm{Zn}-\mathrm{Al}$ ) has an electronic concentration $1.48 \mathrm{e} / \mathrm{a}$, and the nominal $\mathrm{M}_{\mathrm{S}}$ is about $270 \mathrm{~K}$. The sample had undergone previously more than 1000 temperature induced and stress free transformation-retransformation cycles, after a thermal treatment of $15 \mathrm{~min}$ at $1123 \mathrm{~K}$ and water quench to $298 \mathrm{~K}$.

\section{RESULTS AND DISCUSSION}

The measured electrical resistance $R$ shows a behaviour related to the temperature and to the Ms evolutions induced by time and temperature [13]. The particular atomic order effects can be easily seen by a reduced resistance $\left(R^{*}\right)$ associated to a reference temperature $T^{0}$. For instance, substracting a linear temperature dependance of the resistance (thermal phonon contribution). The $\mathrm{R}^{*}$ reads,

$$
R^{*}(t)=R(T, t)-\alpha\left(T-T^{0}\right)
$$

$R^{*}$ allows to compare the time evolutions and to establish a paralelism between resistance and $M_{S}$. Figure 1 shows a record of the temperature $T$ (upper), the reduced resistance $R^{*}$ (middle), and the Ms values (bottom) against time, three years after a water quench from $1123 \mathrm{~K}$. After a micro-thermal treatment of $13 \mathrm{~h}$ at $405 \mathrm{~K}$ ( $\mathrm{a}$ in figure 1), the evolution of the resistance and the behaviour of Ms can be seen. First, the effect of a micro-up quenching (b), where the temperature $T$ goes to $363 \mathrm{~K}$ and returns to $298 \mathrm{~K}$ in 8 min can be noted. Then, the effect of the aging at $363 \mathrm{~K}$, during 4.7 days (c) is shown. After the aging, the temperature value of $298 \mathrm{~K}$ is recovered.

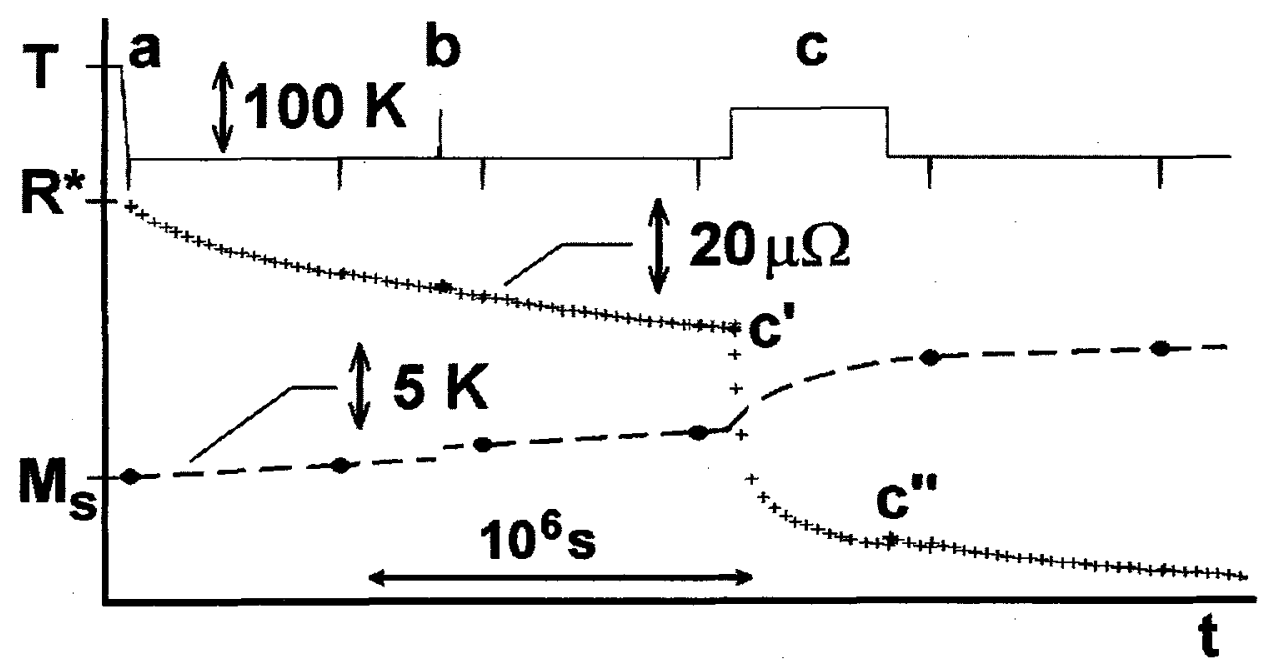

Figure 1: Time and temperature effects. Temperature $T\left(-\right.$, upper), reduced resistance $R^{*}\left(+++\right.$, middle) and $M_{S}$ values (• • , bottom) against time; a) initial micro-thermal treatment: $13 \mathrm{~h}$ at $405 \mathrm{~K}$; b) effect of a micro-up quenching: $\mathrm{T}$ goes to $363 \mathrm{~K}$ and retums to $298 \mathrm{~K}$ in $8 \mathrm{~min}$; c) ageing at $363 \mathrm{~K}$ during 4.7 days. 
The resistance measurements show a singular behaviour: In the micro-up quenching at $363 \mathrm{~K}$ (b in figure 1), the resistance increases slightly and then decreases, whereas after several days at $363 \mathrm{~K}$ (c in figure 1), the resistance $\mathrm{R}^{*}$ decreases between $\mathrm{c}^{\prime}$ and $\mathrm{c}^{\prime}$ like an exponential form. The values of $\mathrm{M}_{\mathrm{S}}$ (full points) show also a particular behaviour with the permanence at $363 \mathrm{~K}$ and with time at $298 \mathrm{~K}$, which can be related to the $\mathrm{R}^{*}$ behaviour.

From the series of observations, it can be established that both the reduced resistance and the Ms follow a time evolution with, at least, two time constants with different activation energies. The two time constants effects are due to two temperature activated processes, associated to changes in atomic order in the material.

The faster process (with $\tau^{(1)}$ [13], see below) might be associated to changes in the nearest-neighbour atomic order $(\mathrm{B} 2)$, and the slower process (with $\left.\tau^{(2)}\right)$ to changes in the next-nearest neighbours (or $L 2_{1}$ order) and/or to the mean path or homogenization of the vacancies concentration from the external surroundings.

From the experimental measurements it can be established that, starting in a steady state at $T_{R T}^{0}$, the transformation temperature $M_{S}$ after a room temperature step (from $T_{R T}^{0}$ to $T$ ) at time $t_{\text {ref }}$ reads,

$$
M_{S}(T, t)=M_{s}\left(T_{R T}^{0}\right)+\Delta M_{S}^{(1)}\left(1-e^{-\left(t-t_{r e f}\right) / \tau^{(1)}}\right)+\Delta M_{S}^{(2)}\left(1-e^{-\left(t-t_{r e f}\right) / \tau^{(2)}}\right)
$$

Where:

$$
\begin{aligned}
& \Delta \mathrm{M}_{\mathrm{S}}^{(1)}=-0.105\left(\mathrm{~T}-\mathrm{T}_{\mathrm{RT}}^{0}\right) ; \tau^{(1)} / \mathrm{s}=\exp \left(-29.304+\frac{13630 \mathrm{~K}}{\mathrm{~T}}\right) \\
& \Delta \mathrm{M}_{\mathrm{S}}^{(2)}=-0.067\left(\mathrm{~T}-\mathrm{T}_{\mathrm{RT}}^{0}\right) ; \tau^{(2)} / \mathrm{s}=\exp \left(-16.933+\frac{10330 \mathrm{~K}}{\mathrm{~T}}\right)
\end{aligned}
$$

The previous relations allow a predictive approximation to the values of the transformation temperature after a temperature step. The time constant values associated with the processes in the material (values in eq. 3 and 4) are very high: from $100^{\circ} \mathrm{C}$ to $25^{\circ} \mathrm{C}$, the $\tau^{(1)}$ changes from $1400 \mathrm{~s}$ to 155 days, where the related $\tau^{(2)}$ changes from 0.54 days to 1.6 years.

\subsection{Experimental and calculated temperature effects}

The previous expressions (eq. 2 and related) allow to compute the Ms behaviour after a step-wise temperature variation in beta phase, departing from a steady state configuration. For a continuous evolution of the sample temperature with time, a model can be constructed as follows: The first one, the ordering processes expressed in equation 2 suggests the treatment as two separate contributions to the transformation temperature Ms, as coming from two approximately independent energetic contributions of atomic order to the free energy differences between beta and martensite phases. It should be noted that the seasonal actions of room temperature or summer and winter effects can easily amount to more than $2 \mathrm{~K}$ but affected by the initial ageing temperature and smoothed and delayed by the time constant values.

The second one, the observation of the response after a temperature step (eq. 2) suggests also the introduction of two equivalent temperatures, $\mathrm{T}^{(1)}$ and $\mathrm{T}^{(2)}$, coupled to the room temperature $\mathrm{T}_{\mathrm{RT}}$ by,

$$
\begin{aligned}
& \frac{d T^{(1)}}{d t}=-\frac{T^{(1)}-T_{R T}}{\tau^{(1)}} \\
& \frac{d T^{(2)}}{d t}=-\frac{T^{(2)}-T_{R T}}{\tau^{(2)}}
\end{aligned}
$$

After numerical integration ( $T_{R T}$ is a time function), carried by a Runge-Kutta algorithm [14] and starting in an initial steady state at $\mathrm{T}_{\mathrm{RT}}^{0}$, the Ms value can be obtained by, 


$$
\operatorname{Ms}(t)=\operatorname{Ms}\left(T_{R T}^{0}\right)+a_{1}\left(T^{(1)}-T_{R T}^{0}\right)+a_{2}\left(T^{(2)}-T_{R T}^{0}\right)
$$

Where $a_{1}=-0.105, a_{2}=-0.067$, and $T^{(1)}$ and $T^{(2)}$ are the time-dependent equivalent temperatures achieved by the integration from the room temperature profile $T_{R T}$ as a function of time and, also, where $T_{\mathrm{RT}}$ determines the actual value of time constants (using, respectively, equation 3 and 4).

In figure 2, the temperature evolution, the $\mathrm{R}^{*}$ values, the measured $\mathrm{Ms}$, and the Ms computed from the described procedure are shown. After about two months, the agreement between computed and measured values is about $\pm 0.15 \mathrm{~K}$.

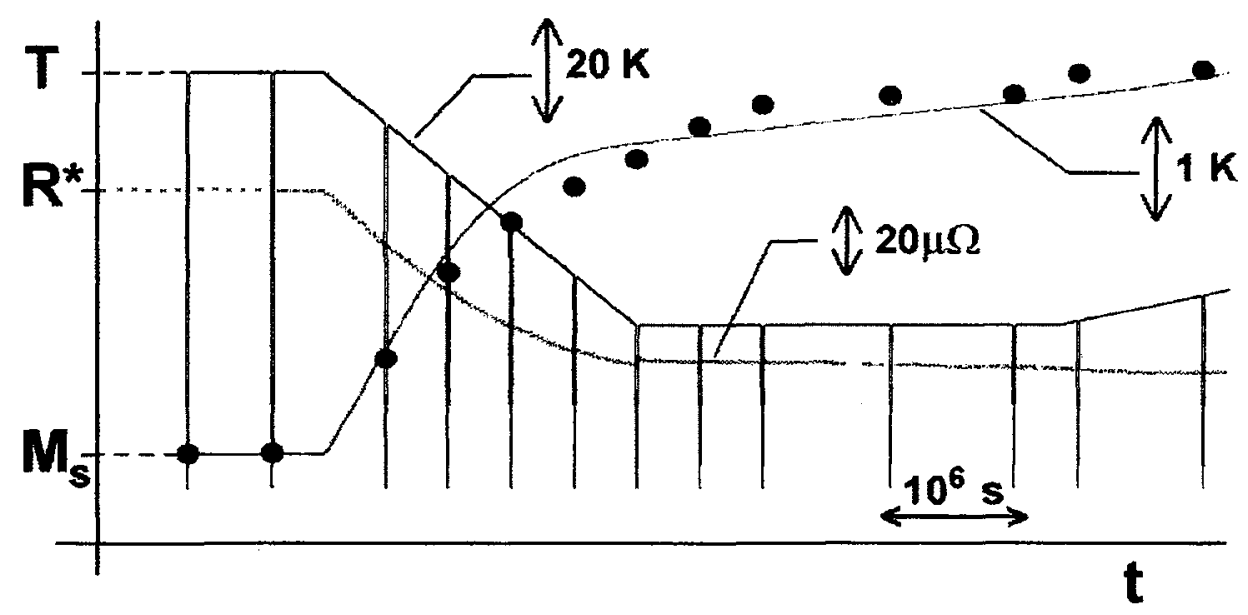

Figure 2: Predictable behavior against time ( $\mathrm{t}$ ). T: experimental temperature; aging: higher value $355.65 \mathrm{~K}$, lower value $295.24 \mathrm{~K}$; cycles: lower value $265 \mathrm{~K} ; \mathrm{R}^{*}$ : reduced resistance defined in eq. 1); Ms: transformation temperature, $\cdots \bullet$, measured, computed with the parameters stated in the text.

\subsection{The Ms dependence on micro-aging and on seasonal effects}

At usual room temperature values of around $298 \mathrm{~K}$, long time effects of previous aging might last for more than a year depending on initial conditions which determine the amplitudes of Ms changes. Figure 3 simulates several "micro-aging" effets $\left(d_{1}, d_{2}, d_{3}\right)$ and the seasonal room temperature effect from summer (s) at $308 \mathrm{~K}$ to winter (w) at $283 \mathrm{~K}$.

The $\mathrm{d}_{1}$ thermal path $(+++)$ simulates a long time aging at $373 \mathrm{~K}$ followed by a slow quench to $298 \mathrm{~K}$ $\left(T_{2}\right)$. The path $d_{2}(x \times x)$ includes a step quench to $T_{b}$ (one month at $\left.338 \mathrm{~K}\right)$. Path $d_{3}(0 \circ o)$ has two steps. One month step at $338 \mathrm{~K}$ plus other month step at $318 \mathrm{~K}\left(\mathrm{~T}_{\mathrm{c}}\right)$. The yearly "steady".fluctuation is similar (near $0.5 \mathrm{~K}$ ) but the path $d_{3}$ is highly efficient relative to standard aging $\left(d_{1}\right)$.

Development of an optimized "micro-aging" treatment to reduce the fluctuations seems feasible after an evaluation of the thermal and time parameters. For the sample analyzed, the classical aging at $373 \mathrm{~K}$, is not the obvious nor the optimal choice.

\section{CONCLUSIONS}

High resolution measurements of resistance against temperature and time have made possible to quantify the behaviour of a Cu-Zn-Al SMA sample in beta phase, near room temperature. Measurements with high resolution were needed to detect and quantify the behaviour of the material after small microstructural changes induced by temperature evolutions near room temperature conditions. The applied working methodology, to characterize the time dependence of SMA behavior, has proved to be successful to reduce the stochastic components on transformation temperature $M_{S}$ and to evaluate the particular parameters of the used alloy. 
The analysis of the experimental results gives the phenomenological rules which regulate the behaviour of the material as a function of time and room temperature. The transformation temperature $M s$ and the reduced electrical resistance $R^{*}$ show a parallel behaviour after a temperature step.

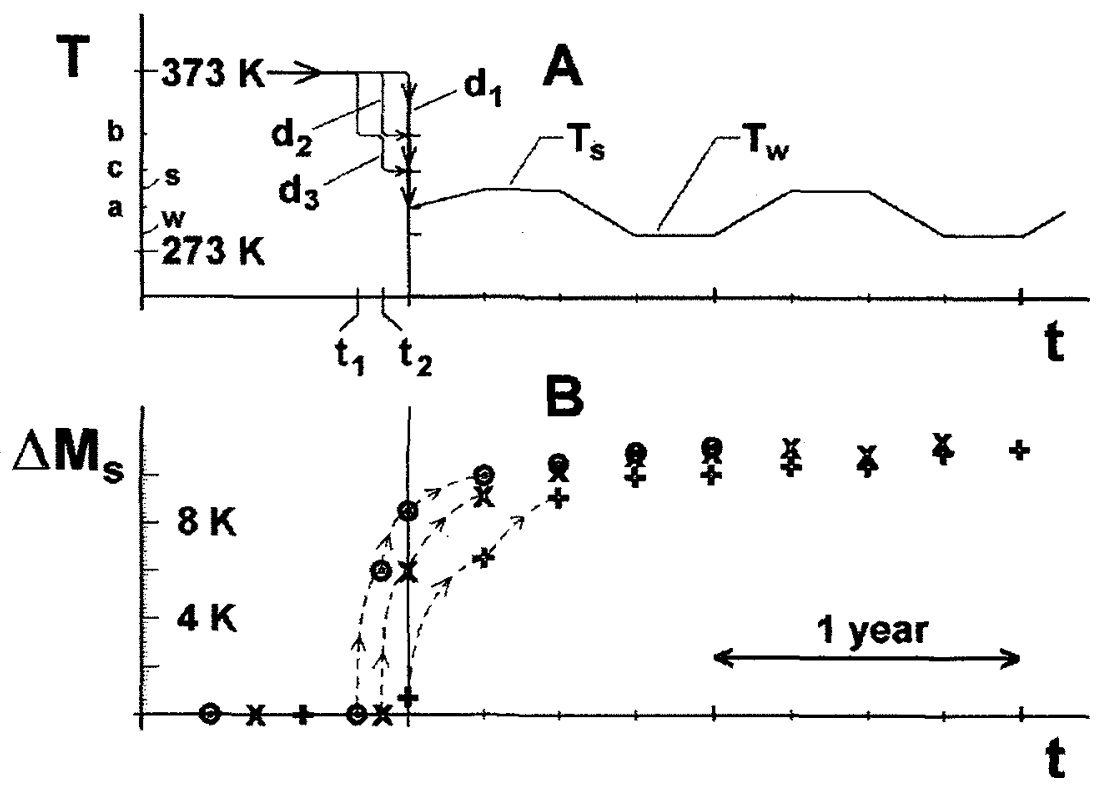

Figure 3: A) temperature against time. B) calculated values of $\mathrm{Ms}$ change (related to the initial value at $373 \mathrm{~K}$ ) after several "micro-aging "procedures; +++ by path $\mathrm{d}_{1}$, after slow quench from $373 \mathrm{~K}$ to $\mathrm{Ta}(298 \mathrm{~K}) ; \mathrm{x} \times \mathrm{x}$ by path $\mathrm{d}_{2}$ stos one month at $\mathrm{Tb}$ $(338 \mathrm{~K}) ;$, 00 o path $\mathrm{d}_{3}$, one month at $\mathrm{Tb}(338 \mathrm{~K})$ plus one month at $\mathrm{Tc}(318 \mathrm{~K})$.

The evolution of the material can be interpreted by two thermal activated processes: Two ordering phenomena represented by two equivalent temperatures with activation energies of $1.17 \mathrm{eV}$ and $0.79 \mathrm{eV}$. The associated time constants are large at room temperature, around 5 months and 1.6 year at $298 \mathrm{~K}$.

A developed procedure permits the evaluation of $\mathrm{Ms}$ evolutions with time and temperature, enabling accurate prediction of the $M_{S}$ changes. The comparative analysis between experimental and calculated results establish that the uncontrolled fluctuations on the transformation temperature can be strongly reduced $\left(\delta \mathrm{M}_{\mathrm{S}} \approx \pm 0.15 \mathrm{~K}\right)$.

\section{Acknowledgements}

Research carried out in the frame of DGICYT HF 1996-0010. V.T. acknowledges Dr. J. Martorell for useful comments about the model and, also, the partial support from ETSECCPB by a contract with Dir. Pol. Terr. (Generalitat of Catalonia).

\section{References}

[1] Delaey L., "Diffusionless Transformations," Material Science and Technology, R.W. Cahn et al. ed., VCH, Weinheim, Germany, Vol. 5 (1991) 339-404.

[2] Ahlers M., Prog. Mater. Sci. 30 (1986) 135-186

[3] Rapacioli R. and Ahlers M., Acta metall 27 (1979) 777-784

[4] Planes A., Viñals J. and Torra V., Phil. Mag. A 48 (1983) 501-508

[5] Viñals J., Torra V., Planes A. and Macqueron J.L., Phil. Mag. A 50 (1984) 653-666

[6] Tsuchiya K., Miyoshi D., Tateyama K., Takezama K. and Marukawa K., Scripta met. mater. 31 (1994) $455-460$ 
[7] Tadaki, T.,"Aging behavior of some shape memory alloys and its origin" in Shape Memory Materials"94, Chu Youyi and Tu Hailing Eds. (International Academic Publishers, Beijing, 1994) pp. 31-38

[8] Dhazi $Y$. and Zhongguo $W$., "Aging effects of Cu-based shape memory alloys" in Shape Memory Materials'94, Chu Youyi and Tu Hailing Eds. (International Academic Publishers, Beijing, 1994) pp. 31-38

[9] Tadaki T., Nakata Y. and Shimizu K., J. Physique IV 5 (1995) C8-81-C8-90

[10] Murakami Y., Nakajima Y. and Otsuka K., Scripta Materialia, 34 (1996) 955-962

[11] L. Buffard, "Influence des interactions, des défauts, de l'ordre-désordre et de la transformation martensitique sur l'hystérésis mécanique de l'alliage à mémoire de forme Cu-Zn-Al-Ni" Ph D (1991) Ecole Centrale de Lyon, France (in french)

[12] Amengual A., Isalgue A., Lovey F.C., Marco F. and Torra V., J. Thermal Anal. 38 (1992) 593-602

[13] Isalgue A., Lovey F.C., Pelegrina J.L. and Torra V., J. Phys. IV Coll C8 5 (1995) C8-853-C8-858

[14] Press W.H., Teukolsky S.A, Vetterling W.T. and Flannery B.P, Numerical Recipes in FORTRAN (Cambridge University Press, Cambridge, U.K., 1992) pp. 704-718. 